\title{
DISTRIBUTION OF REFLECTED POWER FROM THE BED BY RADIO ECHO-SOUNDING IN THE SHIRASE GLACIER DRAINAGE AREA, EAST DRONNING MAUD LAND, ANTARCTICA
}

by

Hirokazu Ohmae,

(Institute of Low Temperature Science, Hokkaido University, Kita-19 Nishi-8, Kita-ku, Sapporo 060, Japan)

Fumihiko Nishio,

(National Institute of Polar Research, 9-10, Kaga 1-chome, Itabashi-ku, Tokyo, Japan)

and

\section{Shinji Mae}

(Department of Applied Physics, Faculty of Engineering, Hokkaido University, Kita-14 Nishi-8, Kita-ku, Sapporo 060, Japan)

\section{ABSTRACT}

A large part of the area of the Shirase Glacier drainage basin has been surveyed by airborne (operating frequency: $179 \mathrm{MHz})$ and ground-based $(60 \mathrm{MHz})$ radio echo-sounding to define the bedrock topography and to investigate the condition of bed/ice interface since 1982 .

It is shown that the reflection intensity from the bed, which is corrected for attenuation in the ice sheet, has a higher value for reflection intensity in the down-stream area of Shirase Glacier than in the up-stream area. The area of strongest intensity of reflection from the bed coincides with the area for which the calculated temperature at the bed is above $-1{ }^{\circ} \mathrm{C}$. The boundary area between the highest and lowest values of corrected reflected intensity corresponds to the area of decreasing basal shear stress. It is found that the distribution of high corrected reflection intensity corresponds to the area of thinning of the ice sheet, which has been measured by ice-flow observation in the Shirase Glacier drainage basin.

\section{INTRODUCTION}

Since 1969, glaciological investigations have been carried out in the area of the Mizuho Plateau $\left(70^{\circ}-73^{\circ} \mathrm{S}\right.$, $35^{\circ}-45^{\circ} \mathrm{E}$ ), East Antarctica. Measurements of the flow of the ice sheet indicate thinning in the Shirase Glacier drainage area (Naruse, 1978). In order to investigate the ice-flow characteristics (using a satellite-positioning system), bed topography (using radio echo-sounding), and other aspects of the snow and ice (by ice-core drilling), a new glaciological project has been carried out in East Dronning Maud Land since 1982.

If the bed of the ice sheet is wet, it is considered that the ice sheet is sliding. If we could obtain some information on the condition of the ice-sheet bed, we would be able to anticipate the ice-flow characteristics which we observed in order to confirm thinning of the ice sheet.

Therefore, we measured the reflecting power of radio waves from the ice-sheet bed by radio echo-sounding, and estimated the condition of the ice-sheet bed from the reflection coefficient of "bed models"; the reflection intensity was corrected for attentuation of radio waves within the ice sheet. The attenuation was calculated from the A-scope data, based on the radar equation for the internal parts of the ice sheet.

\section{SURVEYED AREA}

Figure 1 is a map of the surveyed area of the Shirase Glacier drainage area, east Dronning Maud Land. The route between $G 2$ and $G 7$ is the one investigated in the present study. It is along the flow line of Shirase Glacier.

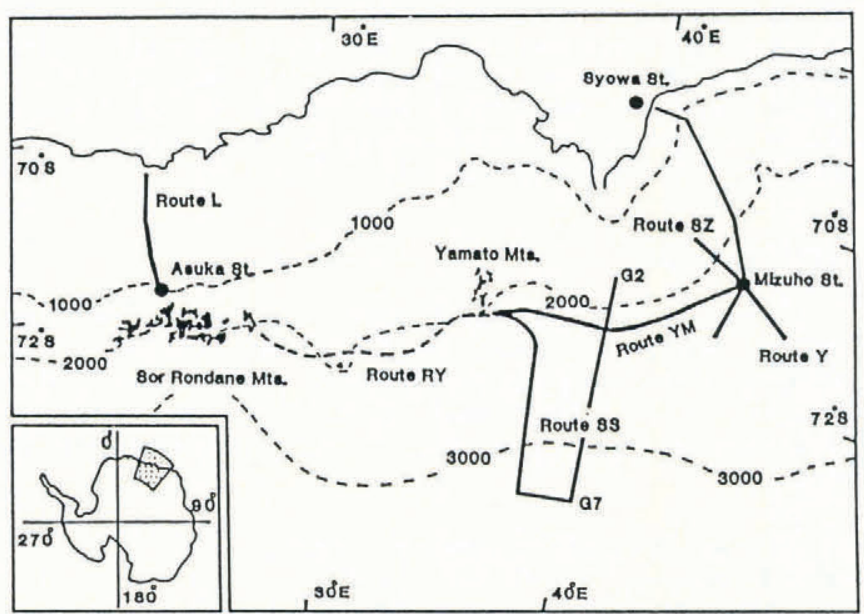

Fig. 1. Map of the surveyed area. Radio echo-sounding carried out along the routes shown by thick lines.

Profiles of the bed and surface elevations along routes SS, SZ, and $\mathrm{Y}$ are shown in Figure 2 for the ground-based radio echo-sounding. Characteristic features of the bed topography have been compiled by Nishio and others (1988) and Ohmae and Nishio (1988). Routes SZ and Y are those from Mizuho Station along one of the flow lines of Shirase Glacier.

\section{MEASUREMENTS AND ANALYSIS}

In order to calculate the reflection coefficient of the bed, attenuation in the ice sheet was obtained from data measured by $60 \mathrm{MHz}$ ground-based radio echo-sounder on an A-scope display, which is an oscilloscope display of the 
a

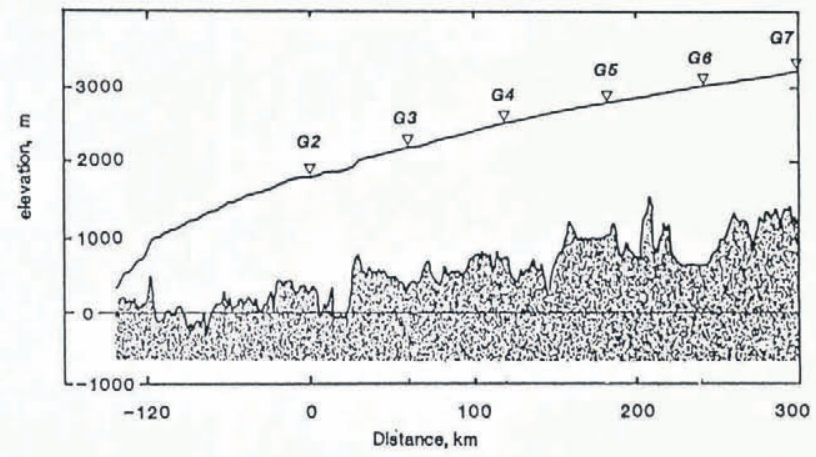

b

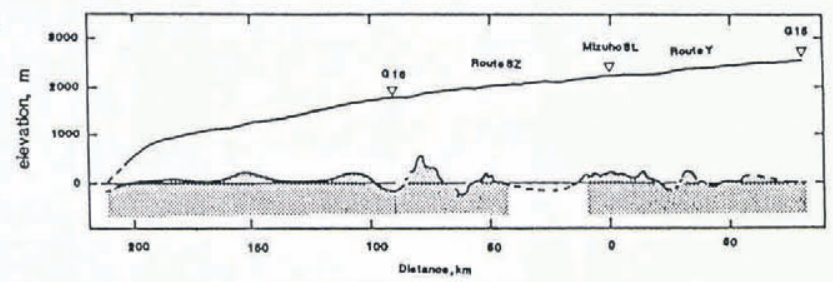

Fig. 2. Surface and bed profiles along the surveyed route: (a) Route SS; (b) Routes SZ and Y.

received power of the radio wave against depth in the ice sheet. For this calculation, we used the radar equation in the ice sheet as follows:

$$
P_{\mathrm{r}} / P_{\mathrm{t}}=\left(K_{\mathrm{a}} G^{2} \lambda^{2} \sigma / r^{2}\right) \exp (-2 \alpha / r)
$$

where $P_{\mathrm{r}}$ is received power (receiver sensitivity: $-102 \mathrm{~dB} \mathrm{~m}$, receiver band width: $5 \mathrm{MHz}$, receiver dynamic range: $60 \mathrm{~dB}$ ), $P_{\mathrm{t}}$ is transmitted power $(1 \mathrm{~kW} \pm 20 \%), K_{\mathrm{a}}$ is a constant which is related to the pulse length $(0.3 \pm 0.05 \mu \mathrm{s})$ and pulse-repeat frequency $(1 \mathrm{kHz}), G$ is antenna gain $(8 \mathrm{~dB}), \lambda$ is wave length, $(5 \mathrm{~m}$ in air, $60 \mathrm{MHz}), \sigma$ is the reflected scattering cross-section, $\alpha$ is the attenuation coefficient, and $r$ is the distance between antenna and target.

In Figure 3, each curve indicates the calculated reflection-intensity profile, plotted logarithmically, with depth given as an attenuation coefficient as a parameter. The reflection intensity was calculated by using the following model of the ice sheet: the ice sheet is formed of two layers, the upper of which is composed of snow whose density changes with depth, and a lower one of ice with a constant density. The depth of the boundary between these two layers is $200 \mathrm{~m}$. This depth seems to be too great in a real ice sheet but the difference between the profiles for different depths of the boundary was in fact very small. Temperature is uniform with depth.

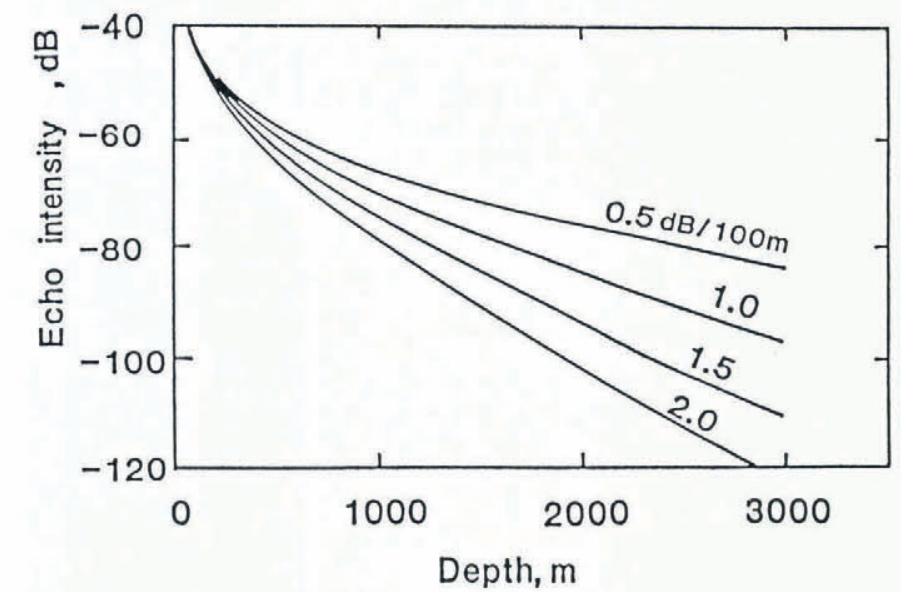

Fig. 3. Calculated reflection intensity plotted against depth of the ice-sheet model. Each value in the illustration shows the attenuation coefficient which is used in the calculation.
From the intensity profiles, we found that the reflection intensity changed by the term of the distance $\left(r^{2}\right)$ at shallow depths, but at depths below about $700 \mathrm{~m}$ the reflected power changed linearly in $\mathrm{dB}$ with depth by the term of the attenuation $(2 \alpha r)$. On the basis of these calculated profiles, we could calculate the attenuation coefficient in the ice sheet from the received power by using a linear regression in the depth range below about $700 \mathrm{~m}$ using the A-scope data (Ohmae and others, 1984). The power received was translated into the reflection intensity by correcting the attenuation coefficient at the point of measurement.

\section{RESULTS}

Figure 4 shows the calculated attenuation coefficients plotted against surface elevation at the point of measurement. In previous work, the attenuation was calculated by using the calculated temperature profile (Robin and others, 1969). However, these coefficients are not

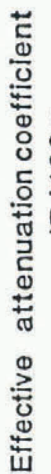

Fig. 4. Attenuation coefficient plotted against the surface elevations of the measured points. Solid circles indicate the points along the main flow line of Shirase Glacier.

calculated values and are basically the measured values. Values for lower elevations are scattered and, on average, high. Values become lower at higher surface elevations. Between elevations of 2000 and $3000 \mathrm{~m}$, values are almost constant.

Figure 5a shows the reflection intensity corrected for attenuation along the main flow line of Shirase Glacier, route SS. It was found that the area of high reflection intensity is located near G2, which is located in the lower
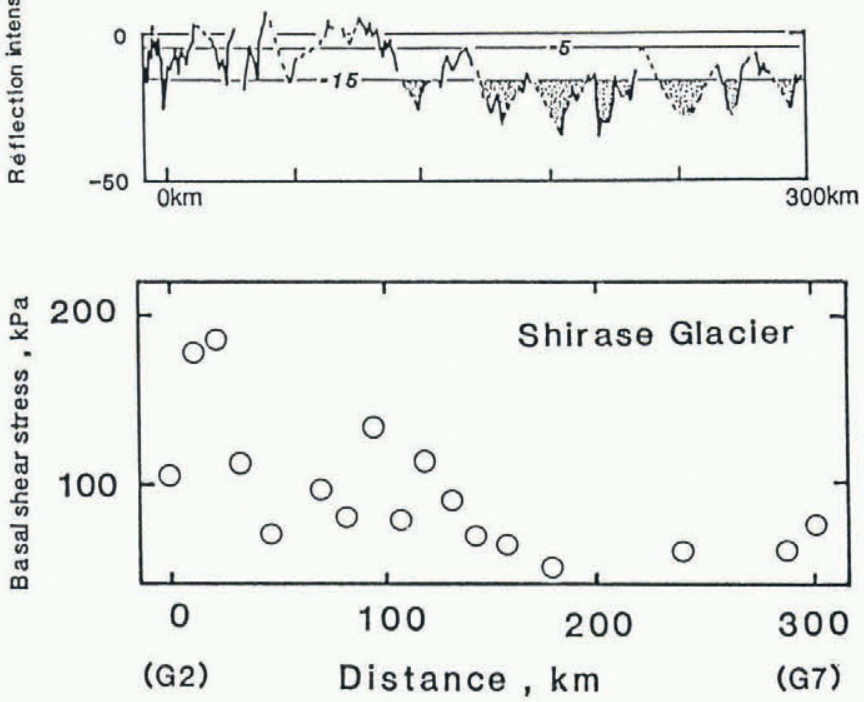

Fig. 5. Distributions of the corrected reflection intensity of the bed of the ice sheet (top), and the driving stress along route SS (bottom). 
middle part of Shirase Glacier. The area with a reflection intensity of $-10 \mathrm{~dB}$ covers the area where the surface elevation is about $2500 \mathrm{~m}$ and, furthermore, we found that the area of $-10 \mathrm{~dB}$ extends from the lower part of the glacier to near Mizuho Station.

\section{DISCUSSION}

We should consider the reflection coefficient of the bed of the ice sheet to explain the area of high reflection intensity. First, we calculated the reflection coefficient of a bed model in which the bed layer is melting and there is a water layer between the ice mass and the bed.

$R_{j k}$ should be the reflection coefficient at the interface between a medium $j$ and a medium $k$, and is calculated as follows:

$$
R_{j k}=\left|\frac{\left(\varepsilon_{j}\right)^{\frac{1}{2}}-\left(\varepsilon_{k}\right)^{\frac{1}{2}}}{\left(\varepsilon_{j}\right)^{\frac{1}{2}}+\left(\varepsilon_{k}\right)^{\frac{1}{2}}}\right|
$$

where $\varepsilon_{j}$ and $\varepsilon_{k}$ are the dielectric constant of media $j$ and $k$, respectively.

At the ice/bed interface, we calculated $R_{j k}$ based on Equation (1). If the ice mass contains a small amount of water (we should call this condition a "wet"-bed model), we obtained for $R_{j k}$ about -10 to $-15 \mathrm{~dB}$. $R_{j k}$ varies with the amount of water and bedrock types, and these values for $0-5 \%$ water content ranged between the above values for sandstone and gneiss.

In the case where there is a water layer between the ice mass and the bed ("water-film" bed model), there are two interfaces near the bed. $R_{\mathrm{iw}}$ and $R_{\mathrm{wr}}$ should be the reflection coefficients at the ice/water and the water/bed interfaces, respectively. Hence, the combined reflection coefficient of the bed, $R_{\mathrm{c}}$, is expressed as follows:

$$
R_{\mathrm{c}}=\frac{R_{\mathrm{wr}} \exp (2 j \beta)+R_{\mathrm{iw}}}{R_{\mathrm{wr}} R_{\mathrm{iw}} \exp (2 j \beta)+1}
$$

where $\beta=k n_{\mathrm{w}} d \cos \theta, \quad k$ is wave number $(=2 \pi / \lambda), \lambda$ is wave length, $n_{\mathrm{w}}$ is refractive index of water, $d$ is thickness of water film, $\theta$ is incident angle, and $j$ is an imaginary index.

$R_{\mathrm{C}}$ is plotted against the thickness of the water film in Figure 6. Values for many water-film thickness are equal to near $0 \mathrm{~dB}$ except for a thickness of $10 \mathrm{~cm}$ and several other thicknesses. A small value results because the phase of the multiple reflection has an inverse sign and the reflection is obliterated. For a thick water layer, like a subglacial lake (Oswald, 1975), the attenuation in the water is high. Hence, considering that the wave length in ice is several meters, it would be sufficient to notice those values for the case where the thickness of the water film is less than about $10 \mathrm{~m}$. In a real ice sheet, it is considered that a water film is several millimeters to centimeters thick. Thus, for the "water-film" model, the value of $R_{\mathrm{c}}$ is considered to range from almost $0 \mathrm{~dB}$ to $-5 \mathrm{~dB}$. This value agrees with that of the corrected reflection intensity near point G2 in Figure 6 . Therefore, it is considered that the bed of the area with the high values for the corrected reflection intensity is in a condition of melting.

The area where the surface elevation is about $2500 \mathrm{~m}$ in the Shirase Glacier drainage area has a "wet" bed as has been derived from $R_{j k}$ in the "wet" model. This area agrees with that where the bed temperature is above $-1{ }^{\circ} \mathrm{C}$, as calculated by Nagao and others (1984).

This result indicates that the area where thinning of the ice sheet has been occurring and where there is a high driving stress $\left(\tau_{\mathrm{b}}=\rho g H \sin \alpha_{\mathrm{s}}, \rho\right.$ is ice density, $g$ is gravity

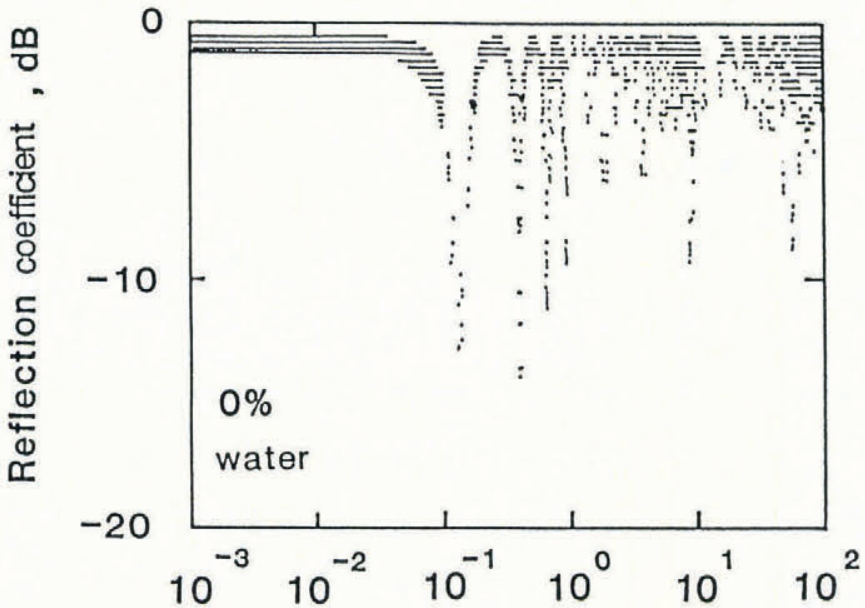

\section{Thickness of water film, $\mathrm{m}$}

Fig. 6. Combined reflection coefficient of the bed for a "water-film" bed model. The hatched area includes the values for various bedrock types.

acceleration, $H$ is ice thickness, $\alpha_{\mathrm{S}}$ is surface slope) in Figure $5 \mathrm{~b}$ in the Shirase Glacier drainage area corresponds to the area with a "wet" bed and "water-film" bed.

It is concluded that the corrected reflection intensity indicates the melting and wet condition of the bed, and the high value of the corrected intensity can be used as an index of thinning of the ice sheet.

For an investigation of the variation of the ice sheet, we require continuous observation of the ice sheet by satellite altimeter (variation of surface elevations), airborne radio echo-sounding (bed condition), and a satellite-navigation system (ice flow).

\section{ACKNOWLEDGEMENT}

The authors are indebted to the referees for many valuable comments on the manuscript.

\section{REFERENCES}

Nagao, M., M. Nakawo, and A. Higashi. 1984. Computer simulation of the ice sheet in the Shirase basin, Antarctica. Ann. Glaciol., 5, 219-221.

Naruse, R. 1978. Surface flow and strain of the ice sheet measured by a triangulation chain in Mizuho Plateau. Mem. Natl. Inst. Polar Res. Special Issue, 7, 198-226.

Nishio, F., H. Ohmae, and M. Ishikawa. 1988. Bedrock and ice surface profiles in the Shirase Glacier basin determined by the ground-based radio-echo sounding. Bull. Glacier Res., 6, 33-39.

Ohmae, H. and F. Nishio. 1988. Ice flow characteristics derived from bedrock topography around Mizuho Station, East Antarctica. Bull. Glacier Res., 6, 27-32.

Ohmae, H., F. Nishio, M. Ishikawa, T. Katsushima, and T. S. Takahashi. 1984. Regional difference of attenuation of radio waves within Antarctic ice sheet. Mem. Natl. Inst. Polar Res. Special Issue, 34, 152-159.

Oswald, G.K.A. 1975. Investigation of sub-ice bedrock characteristics by radio-echo sounding. J. Glaciol., 15(73), 75-87.

Robin, G. de Q., S. Evans, and J.T. Bailey. 1969. Interpretation of radio echo sounding in polar ice sheets. Philos. Trans. R. Soc. London, Ser. A, 265(1166), 437-505. 